\title{
Systems Concepts and Libraries
}

Systems are defined, and their requisite qualities and parts are identified. Libraries possess characteristics which lend themselves to systems analysis, but many present processes were designed under social and economic circumstances which no longer exist. Computers now offer new horizons for library systems, but for them to attain maximum utility will require extensive studies of the user participation in the process of information transfer. Good systems can be based only upon the total social investment in the process.

$\mathrm{U}$ NHAPPILY, THE WORD "system" has acquired so many meanings that it has become a coat which fits nearly every wearer. The classic library system consisting of a group of libraries or a major process such as a circulation system is not the system of the modern systems analyst. A system is an on-going process that produces some wanted operation and is thought of as a whole rather than as an assemblage of pieces and procedures. A system is a dynamic event. The telephone system of the United States and Canada is an oft and appropriately cited example of a huge, complex system designed of many subsystems to function as a totality. Any one of its more than ninety million customers can communicate with any other no matter with which company he is a subscriber or whether he has an ancient magneto telephone or a modern pushbutton instrument.

Modern systems, in addition to being all-encompassing, on-going processes, are information based. Many systems have information in their processing phase, such as a telephone message or a book

Mr. Kilgour is Associate Librarian for Research and Development, Yale University Library. This paper was read at the Fourth Annual Biomathematics Symposium in Houston in June 1966. in a library system. The important aspect of the information base is not the information in process in the system, however, but rather information about what is in process. It is the use of this information, about the form of information in process, to control the system, that distinguishes the modern system from a collection of procedures.

The computer is the instrument of choice in processing information and is obviously the device to employ in monitoring and controlling an informationbased system. The computer culls information from the processing and calculates action to be taken, or not to be taken. Although modern systems thinking began to arise about half a decade before the computer was generally available, the rapid extension of systems thinking had been due mostly to the use of computers.

Techniques for designing new library systems do not differ much from older techniques. What is different are the questions that are asked, and the subsequent answers obtained. In particular, it is necessary (1) to formulate the problem, clearly, (2) to choose appropriate objectives, (3) to define factors relevant in the environment, and (4) to employ ingenuity in inventing new systems and segments thereof. It is also important to 
judge accurately the reliability of cost and other data, but this judgment was equally important in setting up efficient procedures.

Tests to be employed in trade-off studies among proposed procedures design include (1) quality, such as the quality of files, (2) performance, such as need and reliability, (3) compatability, as with other systems and input data, (4) flexibility, to achieve future expansion, (5) simplicity, particularly in regard to operation, (6) time required to install the system, and (7) costs, including initial costs and repetitive costs. ${ }^{1}$

Systems are often spoken of as being "total," but it is not always easy in practice to achieve totality. Nevertheless, a system should be thought of as being comprehensive. Examples of such comprehensiveness are the telephone system of the United States and Canada to which reference has already been made, and the power grids which also include both countries.

Management-information components should be designed into systems to facilitate direction of the system. Here the information processor produces information reports to management, so that management has an accurate picture of events in the system. Management in turn may change parameters in the information processor to alter control of the system. Similarly, management may shift human components in the manual processing organization, or even change that organization. ${ }^{2}$

Feedback is present in such systems since the information-processor, or computer, controls the flow of materials in the system on the basis of information derived about that flow. The process of the use of management information described in the previous paragraph is a

${ }^{1}$ A. D. Hall, A Methodology for Systems Engineering (Princeton: Van Nostrand, 1962), pp. 105-107.

${ }^{2}$ A. M. McDonough and L. J. Garrett, Management Systems; Working Concepts and Practices, (Homewood, III.: R. D. Irwin, 1965). similar example of feedback in the system.

A library, a group of libraries, or a national library network can be viewed as an information transfer system. A single library has at least four major subsystems: (1) an information store; (2) communications; (3) real property; and (4) users. The information store consists of two types of information: (1) books, pamphlets, serials, manuscripts, reports, films, records, and pictures; (2) card catalogs, index and abstract journals, printed catalogs, and bibliographies. The communication subsystem could contain telephones and automobiles; real property, buildings and grounds. The user is the customer who generates information transfer with his needs for specific information.

From the systems point of view, these four major subsystems meld into a whole but can also be further subdivided into lesser subsystems. It it important to observe that in the library building design process, all four subsystems are treated as an integrated whole, but that the design of information transfer, the design of the catalog and book arrangement do not specifically integrate with the modern user subsystem. This dislocation exists because there has been no major redesign of cataloging and classification processes during the past half century. Rather, cataloging and subject classification are currently used on a conglomerate of a priori bibliographic, classificatory, and economic principles largely developed in the four decades preceding the first World War. Librarians strive to give the best possible service with such organizations of catalogs and books to each user when he appears, but the time has come to analyze acquisition, cataloging, and classifying library information in terms of users' needs-as integrated with the user subsystem.

The modern library user has impressively different needs from those who 
used libraries at the turn of the century. Information needed by modern users occupies a new position that is central in our society and has become a major national resource-a position which it has come to enjoy only since World War II. From a systems viewpoint, it appears that the library information store and its processing have not kept pace with the changing status of information and information users. Or to put it another way, during the last half century, library science-relative to library use-has become increasingly a priori in principle and increasingly self-existent in practice.

The advent of that remarkable information-processing machine, the electronic digital computer, forces an examination of the library as a system in the modern sense of that word. If it is correct that library information processing has not kept pace in principle with library information usage, computerization of present-day library processes will achieve no more than would replacing a cart and horse with an automobile. Analysis of the library into four major subsystems suggest that three (information store, communications, and users) should be computerized. But to achieve dramatically improved systems performance, it will be necessary to treat users as an integral part of the library and to do extensive investigations on the characteristics of users, on information needs of users, and on their uses of library information.

Investigation of use of library materials, of users' needs, and of characteristics of users will involve answering a host of questions. Once the user is considered part of a library system, it is then necessary to know something of his productivity and to evaluate that productivityan evaluation which only a few have attempted. ${ }^{3}$ It will also be necessary to

\footnotetext{
${ }^{3}$ See, for example, Ben-Ami Lipetz, The Measurement of Efficiency of Scientific Research (Carlisle, Mass.: Intermedia, Inc., 1965).
}

know users' costs. At the present time, cost effectiveness in libraries is judged only on the amount of money spent in processing one item in a given procedure. American libraries have increasingly tended to use cataloging, classification information, and subject-heading work of the Library of Congress because it is cheaper. The appropriate classification for the Library of Congress might be entirely inappropriate for a local library, however. Moreover, the amount of subject analysis done by the Library of Congress, and most other libraries, for that matter, has been reduced to less than an acceptable minimum because of the engulfing growth of card catalogs. This reduction in subject accesses to information has lessened the cost of library procedures, but it most certainly has increased user costs. Indeed, it is probable that this diminution of subject analysis has been one of the major factors in generating the current library crisis.

Little is known of the information needs of users and there are relatively few studies available from which to learn something of those needs. Recently, the Systems Development Corporation reviewed some four hundred and fifty such studies and concluded that there were only fifty-eight that had objective and reliable information. ${ }^{4}$ Moreover, most such studies treat the user as not being a part of a library system, and therefore neglect the costing aspects. This neglect has led to the suggestion of systems taking a week or more to produce information, but it is clear without doing a study that if users' costs are to be kept at a minimum, this access to information should be in terms of minutes and not days.

There is also confusion as to what con-

${ }^{4}$ U.S. Federal Council for Science and Technology. Committee on Scientific and Technical Information, Recommendations for National Document Handling Systems in Science and Technology, Appendix A, (Springfield, Va.: Clearing House for Federal, Scientific, and Technical Information, 1965) II, 2-8. 
stitutes "new" with respect to information supplied to users. Altogether too often, "new" is taken to mean "recent." Indeed, some studies of users' needs have concentrated on recent information as though it constituted all information that was new. New information should be interpreted as information new to the user; indeed, it may have been published decades ago but still be valuable and new. The confusion of "new" and "recent" has unnecessarily narrowed userneeds studies, so that older material has been unwarrantedly neglected.

Finally, design of modern library systems will profit from studies yielding knowledge as to how library materials are used. It is important to know which volumes are used and to what use they are put. Citation studies do not reflect use of information and these studies have tended to show that books were littleused. Studies done at the Yale medical library and elsewhere ${ }^{5}$ have revealed, however, that scientists use books in significant numbers. It was also found at Yale that use of books by researchers was nine-tenths research related.

${ }^{5}$ F. G. Kilgour, "Recorded Use of Books in the Yale Medical Library," American Documentation, XII (October 1961), 266-69; Helen Kovacs, "Analysis of One Year's Circulation at the Downstate Medical Center Library," Bulletin of the Medical Library Association, LIV (January 1966), 42-47; L. M. Raisig, Meredith Smith, Renata Cuff, and F. G. Kilgour, "How Biomedical Investigators Use Library Books at the Yale Medical Library," Bulletin of the Medical Library Association, LIV (April 1966), 104-107.
Acceptance of the premise that the user is an integral part of a library system leads to extensive reorientation of design of library systems. Certainly, it is a goal of the new systems to supply the user with information when he needs it. If he needs it in his laboratory or his study, it should be available to him there. It may well be that librarians will find themselves engaged in an atavistic activity leading to systems in which the user will hardly, if ever, enter a library. It seems quite probable that before the end of the century, information servicing to faculty and students on new campuses of multi-universities will not involve a huge library building. Rather, there will be an information store available by consoles in laboratories, studies, and dormitories where faculty and students can have rapid access to information required.

Of course, universities already fortunate in the possession of huge numbers of library materials will continue to possess these holdings and increase them. These great holdings will be the source of the automated systems of the future.

In summary, the most novel aspects of new library systems will be their character of being information based and controlled by information processing machines. Also, they will include the user as part of the system, and the systems will be specifically designed for rapidly and specifically fulfilling users' needs. 